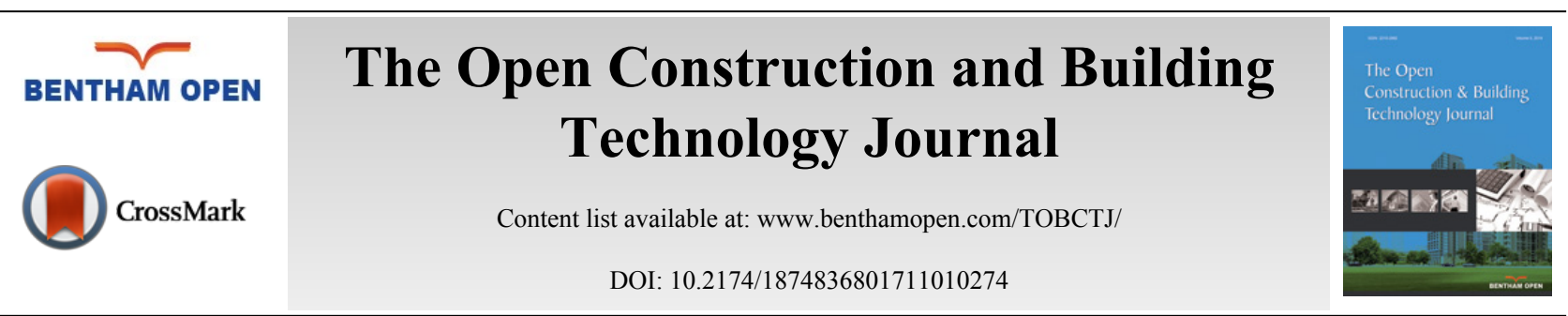

RESEARCH ARTICLE

\title{
Improvement of Locally Available Raw Bentonite for Use as Drilling Mud
}

\author{
Kaffayatullah Khan ${ }^{1, *}$, Shaukat Ali Khan ${ }^{2}$, Muhammad Umair Saleem ${ }^{1}$ and Muhammad Ashraf ${ }^{3}$ \\ ${ }^{I}$ Department of Civil and Environmental Engineering, King Faisal University, Hofuf Saudi Arabia \\ ${ }^{2}$ Department of Civil Engineering, University of Engineering and Technology Taxila, Taxila, Pakistan \\ ${ }^{3}$ Department of Civil Engineering, CIIT, Abbottabad, Pakistan
}

Received: May 24, 2017

Revised: July 06, 2017

Accepted: July 24, 2017

\section{Abstract:}

\section{Background:}

Bentonite clays are widely used in a drilling operation and play a vital role as a drilling fluid. Bentonite clay mud performs several functions during the drilling operation and facilitates the drilling process.

\section{Objective:}

In this study, the locally available raw bentonite clays were investigated to evaluate its potential use as a mud for borehole drilling operation after its improvement with the additives.

\section{Method:}

Rheological properties such as plastic viscosity, yield point and gel strength were evaluated by using a viscometer and filtrate loss test was performed by using filter press on both locally available raw bentonite clays and the commercial bentonite named as Mill gel.

\section{Results:}

From the test results obtained for the up gradation of clays with the different beneficiating materials, the drastic increase in the plastic viscosity, yield point and gel strength has been observed. It shows that Xanthum gum produced better results for the improvement of rheological properties of such clays. Carboxymethyl cellulose and starch were used as additives and it has been observed that carboxymethyl cellulose has improved both viscosity and filtrate loss control, whereas starch muds have the best filtration control properties.

\section{Conclusion:}

Improved bentonite clays have rheological and filtration characteristics that have satisfied American Petroleum Institute specification at optimum conditions of clay. It was concluded that improved clays are the suitable material for the drilling operations and suitable to substitute commercial bentonite.

Keywords: Bentonite, Rheological properties, Filtrate loss, Carboxy methyl cellulose, Xanthum gum, Starch.

\section{INTRODUCTION}

Bentonite is a rock mainly formed from the alteration of volcanic ash and is very rich in montmorillonite $(>80 \%)$ from the smectite group [1 - 4]. It is generally classified into two types, namely sodium (Na) or calcium (Ca). Ca-

\footnotetext{
* Address Correspondence to this author at the Department of Civil and Environmental Engineering, King Faisal University, Hofuf, Saudi Arabia; Tel: +966-5966-88748; E-mails: kkhan@kfu.edu.sa, kifayat.2000@gmail.com
} 
bentonite with $\mathrm{Ca}++$ as a dominant exchangeable cation has a low swelling and water absorption ability, while the Nabentonite carrying $\mathrm{Na}++$ as a dominant exchangeable cation, exhibits more swelling and absorb a large amount of water to form a more viscous fluid [3]. Most of the montmorillonite deposits available worldwide are calcium types. However, there are some deposits of Na-montmorillonite available in Mexico, Argentina, South Africa, Turkey, Japan, and Australia [5].

Bentonite is in high demand for various industrial applications. It can be used as a drilling mud for oil wells and as a sealant or liner for dams and landfills projects. It has also special use in cosmetics, pharmaceuticals, foods, ceramics, paints, paper and iron industries [6 - 13]. The valuable use of bentonite in different industries attributes to its important physical properties such as small particle size, high surface area, high viscosity, absorption and swelling properties, cation exchange capacity, high bond strength, plasticity and impermeability $[8,9,14,15]$.

There are different kinds and grades of bentonite deposits in Pakistan [16 - 23]. Huge reserves of bentonite are available in Karrak [24], Mirpur [25], Rawalpindi, Attock and Jhelum areas [17]. But, still, there are several bentonite deposits that need to be explored. Recently, some studies have been done to explore the potential of the indigenous material to be used as a bleaching or decolourization agent [26], removal of magnesium [27] pozzolan for cement replacement [28 - 31] and its use in pharmaceutical industry [24]. But, there are very few works found in literature which can describe the utilization of bentonite clay with the intention of drilling fluid formulation, although its large deposits have been discovered in various parts of Pakistan. As a result, most of the bentonite is imported from other countries by the petroleum industry for carrying out drilling works in Pakistan. Clearly, there exists need to experimentally investigate the suitability of the bentonite deposits in Pakistan as a replacement of imported bentonite for use in oil well-drilling. Most of the bentonite deposits available in Pakistan are Ca type or Na-Ca type [24]. So, it is commonly known that even a good quality Na-bentonite in natural form does not fulfill the standard requirement for drilling mud [32]. There is a need to either activate or add some polymer to upgrade the raw Na-Ca bentonite and even to Ca-bentonite to meet the American Petroleum Institute (API) standards. The minimum viscosity at $600 \mathrm{rpm}$ should be 30Cp and maximum filtration loss should be $15 \mathrm{~cm}^{3}$ in order to fulfill the requirement of API standard for drilling mud [33]. Many investigators modified the raw natural bentonite by adding polymers and similar compounds and found it very effective in getting high viscosity and low filtrate losses [34 - 41].

The aim of this study was to investigate the use of bentonite as a drilling fluid and explore its use with different kinds of additives to enhance the performance of bentonite as drilling mud to acceptable standards. This study will provide a platform to encourage the use of local bentonite as drilling mud and thus to save a lot of money which is spent on importation of bentonite from other countries for oil well drilling. Research based on effective and efficient local sourcing will result in promoting development of industrial sector, mining and quarrying techniques. Marketing future of bentonite is quite bright in Pakistan, provided the indigenous material is upgraded up to international standard.

\section{MATERIALS AND METHOD}

\subsection{Sample Collection and Preparation}

The bentonite samples were collected from seven different sources of Khyber Pakhtunkhwa, Punjab provinces and also from Azad Jammu \& Kashmir and Federally Administrated Tribal Areas (FATA) of Pakistan. Unfortunately, the local unskilled workers have applied only crude and risky mining methods for extraction of bentonite. The miner digs out narrow holes along the deep slope and excavates the bentonite by hand as shown in Fig. (1). The available bentonite layer was used for collecting its fresh samples. Two sources (Jhelum and Jundola) were selected for detail investigation of its potential use as an oil well drilling mud. The collected samples were first crushed to smaller particles and left for a week in sunlight for drying. The samples were then placed in an oven at the standard temperature for complete drying before grinding. Samples were then ground by the mechanical grinder and passed through Sieve No. 200 using a mechanical sieve shaker to meet the API standards [42]. Commercially available bentonite (Mill Gel) were used as a reference bentonite and xanthan gum, carboxy methyl cellulose (CMC HV), starch were used as an additive for improving the characteristic of raw bentonite.

\subsection{Chemical Analysis}

XRF (X-ray fluorescence) were made for all the samples by using X-ray spectrometer in the Geoscience Laboratories Islamabad as shown in Table 1. Chemical analysis results showed that the A12O3/SiO2 ratio is approximately $1 / 3$ or more for all the samples, and found similar to Wyoming bentonite and satisfy the basic 
requirement in montmorillonite. As the mass ratio of $\mathrm{Na} / \mathrm{Ca}$ for Jhelum and Jundola bentonite is 1.5 and 1.6 , respectively and the mass ratio of $(\mathrm{Na}+\mathrm{K}) /(\mathrm{Ca}+\mathrm{Mg})$ for both the bentonite is around 2, so both bentonite fall within the category of Sodium Bentonite [43].
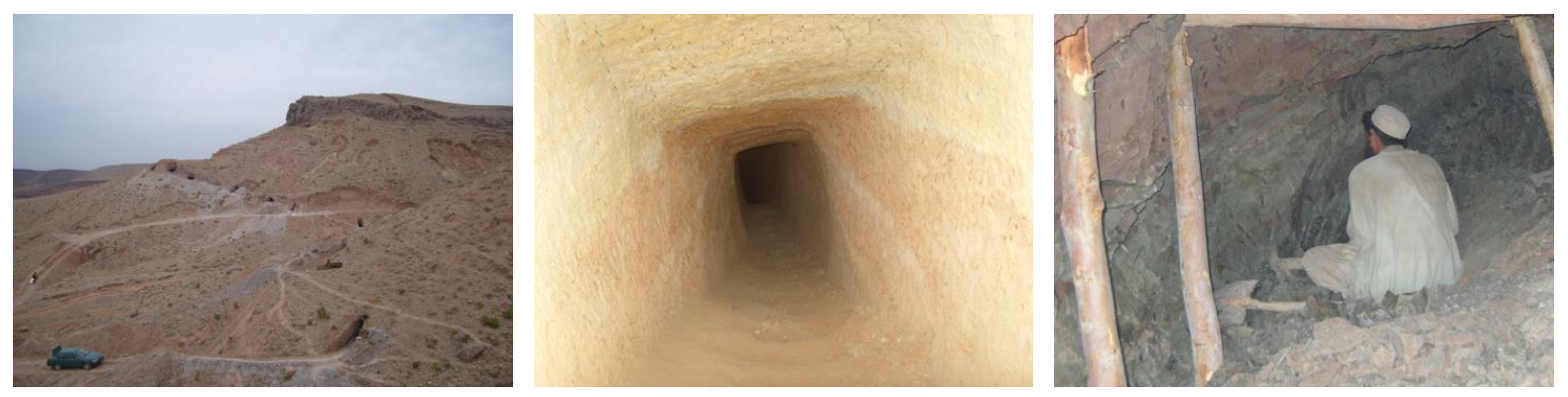

Fig. (1). Mining methods used by local unskilled labor for extraction of bentonite.

Table 1. Chemical analysis (XRF) of seven different bentonites sources in Pakistan.

\begin{tabular}{|c|c|c|c|c|c|c|c|}
\hline Oxides & Attock & Cherat & Gari Chundun & Jhelum & Azakhel & Jhandola & Bimber \\
\hline $\mathrm{SiO}_{2}$ & 49.9 & 51.4 & 52.0 & 48.6 & 50.4 & 53.5 & 50.9 \\
\hline $\mathrm{Al}_{2} \mathrm{O}_{3}$ & 18.2 & 21.4 & 16.2 & 18.7 & 18.9 & 18.6 & 17.8 \\
\hline $\mathrm{Fe}_{2} \mathrm{O}_{3}$ & 3.2 & 5.8 & 4.6 & 3.3 & 4.7 & 7.5 & 3.3 \\
\hline $\mathrm{TiO}_{2}$ & 0.3 & 0.5 & 0.5 & 0.4 & 0.6 & 0.6 & 0.4 \\
\hline $\mathrm{MgO}$ & 0.1 & 0.2 & 0.1 & 0.1 & 0.1 & 0.1 & 0.1 \\
\hline $\mathrm{Na}_{2} \mathrm{O}$ & 4.2 & 3.5 & 4.1 & 4.0 & 3.5 & 3.9 & 4.0 \\
\hline $\mathrm{CaO}$ & 2.8 & 1.2 & 3.3 & 2.7 & 2.1 & 2.4 & 1.8 \\
\hline $\mathrm{K}_{2} \mathrm{O}$ & 0.3 & 0.5 & 1.2 & 1.6 & 4.0 & 0.5 & 1.4 \\
\hline $\mathrm{SO}_{3}$ & 0.5 & 1.3 & 1.4 & 0.7 & 1.1 & 1.9 & 0.7 \\
\hline $\mathrm{P}_{2} \mathrm{O}_{5}$ & 0.1 & 0.1 & 0.1 & 0.1 & 0.2 & 0.1 & 0.1 \\
\hline $\mathrm{LOI}$ & 20.5 & 14.0 & 16.5 & 19.7 & 14.4 & 14.1 & 18.9 \\
\hline
\end{tabular}

\subsection{Mixing Method and Drilling Fluid Preparation}

The performance of drilling fluids and additives was tested according to the API standard procedures which are compiled in the API specification 13A [42]. A base liquid and an additive need to be fully mixed or dissolved into a liquid to get a homogenized fluid, known as drilling mud. A Hamilton Beach commercial mixer as shown in Fig. (2a) was used to prepare drilling mud for various laboratory tests. This mixer conforms to the API specifications 13A. The control mud sample was prepared by adding $21 \mathrm{~g} \mathrm{(6 \% )} \mathrm{Mill} \mathrm{Gel} \mathrm{to} 350 \mathrm{ml}$ of water while increasing weights of $21 \mathrm{~g}$, 40 $\mathrm{g}, 60 \mathrm{~g}, 80 \mathrm{~g}$ and $100 \mathrm{~g}$ of Jhelum and Jundola were added to $350 \mathrm{~mL}$ water to prepare different mud weights. Commercially available additives (Xanthan gum, CMC HV, starch) were used to apply improvement tests on Jhelum and Jundola mud samples of $6 \%(21 \mathrm{~g} / 350 \mathrm{~mL})$ by mass according to API standards

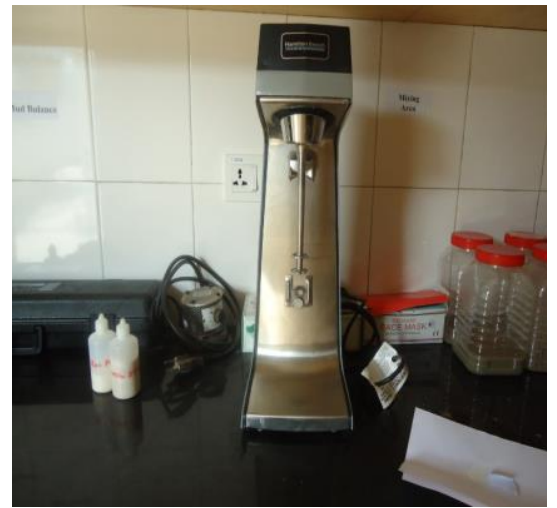

(a)

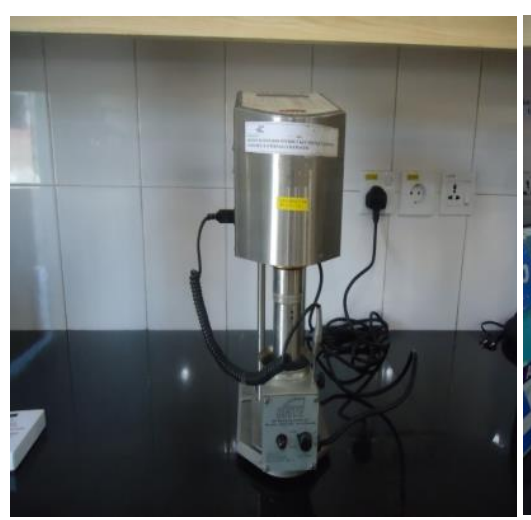

(b)

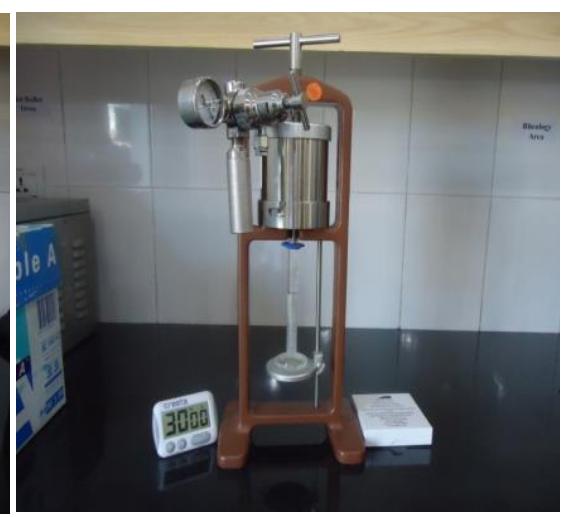

(c)

Fig. (2). (a) Hamilton Beach Commercial mixer; (b) Viscometer Model 900; (c) Filter Press. 


\subsection{Rheological Characterization}

Different parameters were used to evaluate the mud rheology which included plastic viscosity, yield point and gel strength. These parameters were measured with the help of a multi-speed viscometer (Model 900) as shown in Fig. (2b) by changing a number of additives that included Xanthan gum, CMC HV, starch and their blend.

\subsection{Filtration Tests}

A filter press as given in Fig. (2c) was used to determine the filtrate loss of different solution by applying a standard cell pressure of $100 \pm 1.0$ PSI $(690 \pm 6.9 \mathrm{kPa})$ to the top cap using a back pressure regulator attached to a nitrogen tank within 30 seconds for a 30 minute test as recommended by the API standards [43]. At the end of 30 min, filtrate volume was measured in a graduated cylinder through the drain tube.

\section{RESULTS AND DISCUSSION}

\subsection{Rheological Properties of the Raw Jhelum and Jundola Bentonite:}

The rheological parameters including plastic viscosity, apparent viscosity, yield point and gel strength of the mud at different concentrations of Jhelum and Jundola bentonites $(21 \mathrm{~g}, 40 \mathrm{~g}, 60 \mathrm{~g}, 80 \mathrm{~g}$ and $100 \mathrm{~g})$ in $350 \mathrm{~mL}$ of water was compared to commercial bentonite (Mill Gel) at $21 \mathrm{~g} / 350 \mathrm{~mL}(6 \%$ by mass) according to API specification as shown in Figs. $(4,5)$. The rheological properties showed a major increase in the apparent viscosity, plastic viscosity, yield point and gel strength because of the increase in the concentration of both bentonites from $20 \mathrm{~g}$ to $100 \mathrm{~g}$. The optimum rheological properties observed which approximates that of Mill Gel as $80 \mathrm{~g} / 350 \mathrm{~mL}$ and $60 \mathrm{~g} / 350 \mathrm{~mL}$ for Jhelum and Jundola bentonites, respectively.

The dependence of apparent viscosity on shear rate (rpm) at different clay concentrations from $20-100 \mathrm{~g} / 350 \mathrm{~mL}$ is shown in Fig. (3). It was observed that apparent viscosity was high in the initial stages but it starts decreasing and become constant at later ages. This indicated that viscosity at low shear was increased with enhanced clay concentration. Both the Jhelum and Jundola muds demonstrated remarkable improvement in the rheology as the concentration of the clay increased which has shown their capabilities for drilling purposes.

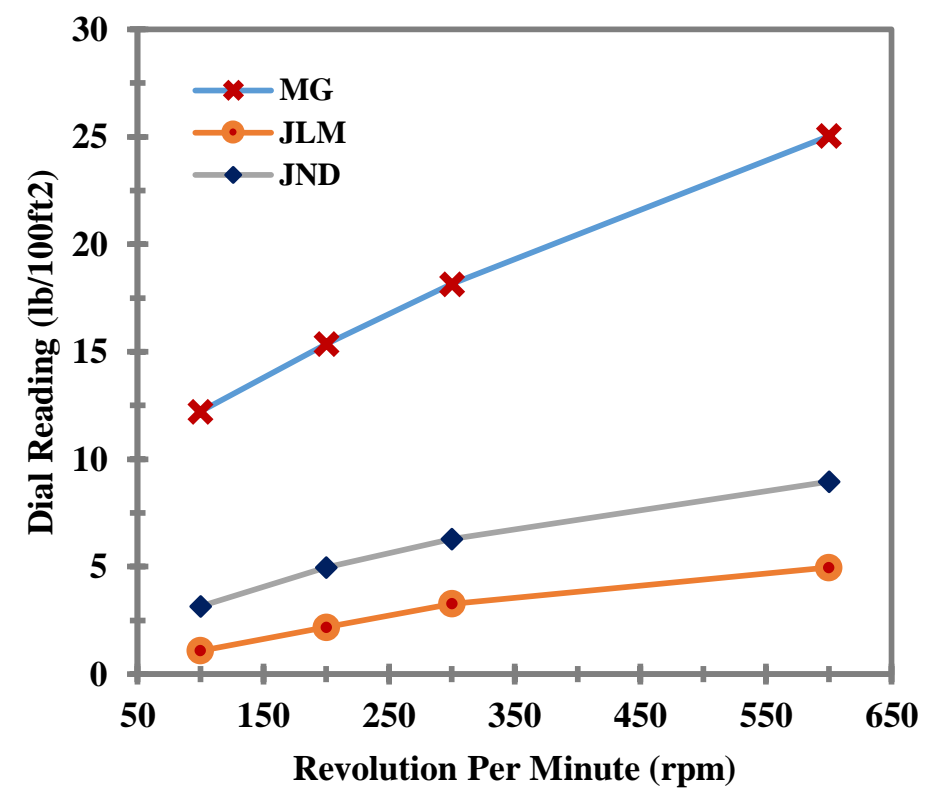

Fig. (3). Performance of Mill Gel (MG), Jhelum (JLM)and the Jundola (JND) clay muds in a multispeed Rheometer (Model 900 Viscometer). 

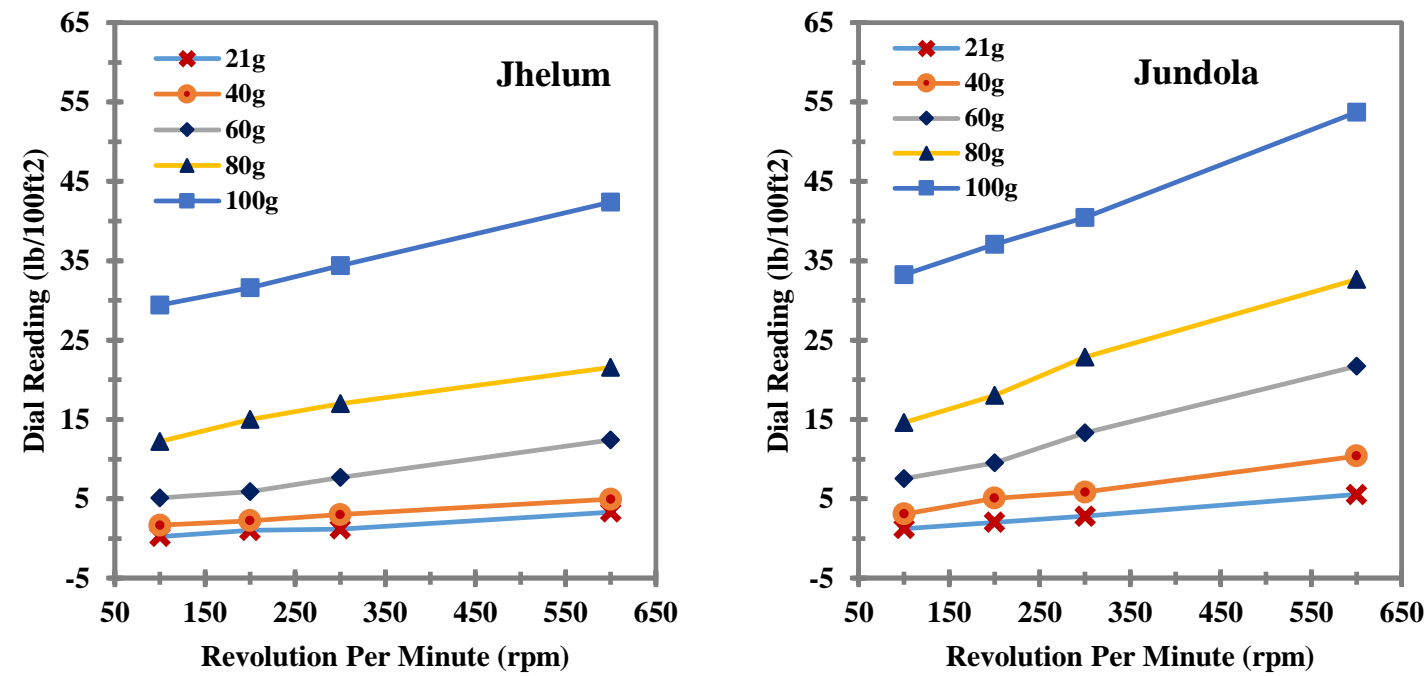

Fig. (4). Variation of rheological parameters with (Jhelum—JLM, Jundola—JND and Mill gel—MG) clay concentration.

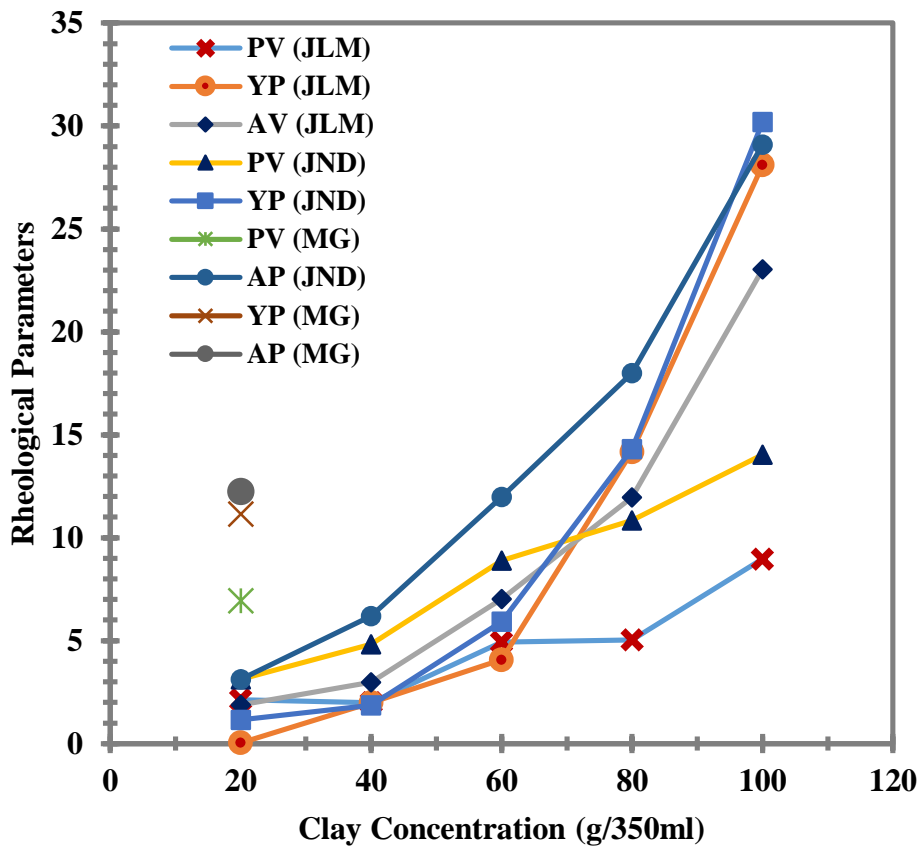

Fig. (5). Performance of Jhelum bentonite and the Jundola bentonite muds in a viscometer.

\subsection{Filtration Properties of the Raw Jhelum and Jundola Bentonite:}

When the weight percent of the clay was increased, the filtration properties of the local clay mud systems showed distinct changes at different mud levels. A decrease in the filtrate loss with the increase in the percentage of Jhelum clay was noted. However, it was higher than the filtrate loss of $21 \mathrm{~g} / 350 \mathrm{~mL}$ (Mill gel) at all of the clay concentrations of the local clays. On the contrary with the Jundola bentonite, the filtrate loss decreased at $100 \mathrm{~g} / 350 \mathrm{~mL}$. It was a low level than the imported bentonite at standard API concentration of $21 \mathrm{~g} / 350 \mathrm{~mL}$ as given in Fig. (6). These results revealed that low bentonite concentrations are needed to be applied in local raw bentonite system. This can be done by adding chemicals or polymers that will check fluid losses during the drilling processes. 


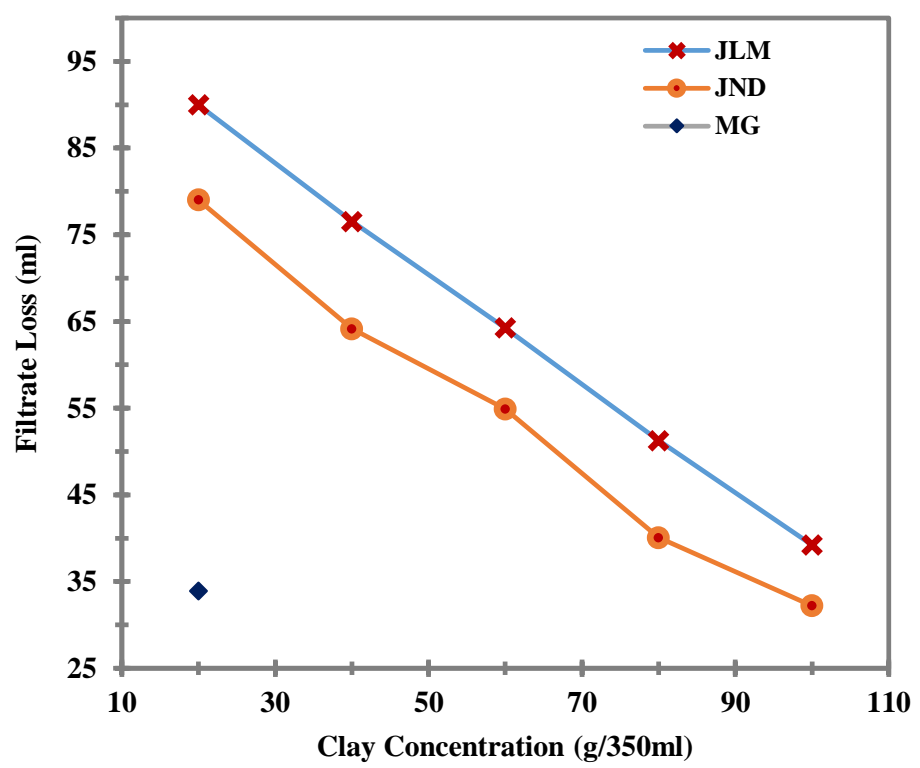

Fig. (6). Filtrate loss values with varying clay concentration.

\subsection{Improvement Tests}

Rheological parameters were measured for Jhelum and Jundola mud. These included plastic viscosity, yield point and gel strength and filtration properties. It was observed that both of the properties were improved with the addition of commercially available additives (Xanthan gum, CMC HV and Starch) which are commonly used by the drilling industry in the oil-well drilling. After measuring the individual and combined effects of these additives, the improved bentonite results were compared with the commercial bentonite (Mill gel) muds.
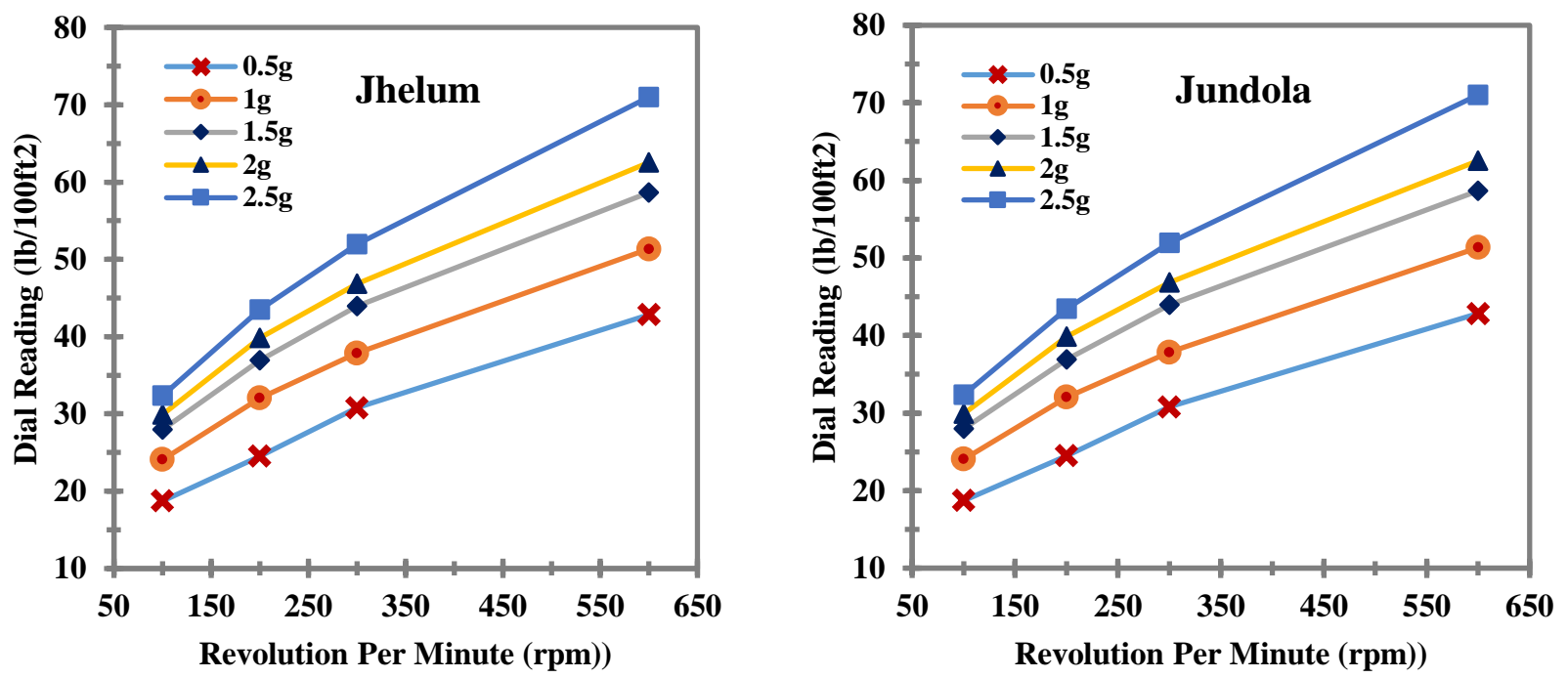

Fig. (7). Behaviors of the Xanthan Gum with Jhelum and Jundola clay mud samples in a multi speed Rheometer.

\subsubsection{Rheological properties of the improved Jhelum and Jundola Bentonite:}

Xanthan gum $(\mathrm{XG})$ was used to improve the rheological properties of raw bentonites. The addition of XG resulted in a significant increase of the dial readings of the mud at all speeds at a constant concentration $(21 \mathrm{~g} / 350 \mathrm{~mL})$ of both Jhelum and Jundola muds as shown in Figs. $(7,8)$. It indicated a notable increase in the apparent viscosity, plastic viscosity and yield point. For instance, the dial reading at $600 \mathrm{rpm}$ increased sharply from 5 to 70 with the addition of $9.5 \%$ Xanthan gum to $21 \mathrm{~g} / 350 \mathrm{~mL}$ Jhelum mud. It represented an increase of 13 folds in the dial readings and has given an increase of 6.5 and 40 times in the plastic viscosity and yield point respectively. Tests results showed an improved 
performance in the mud which will result in better drilling performance. The effect of Xanthan gum also indicated an upward trend in the formation of $10 \mathrm{sec}$ and $10 \mathrm{~min}$ Gel strength. This demonstrated an ability of the drilling mud to suspend drill solid and weighing material when circulation was stopped.
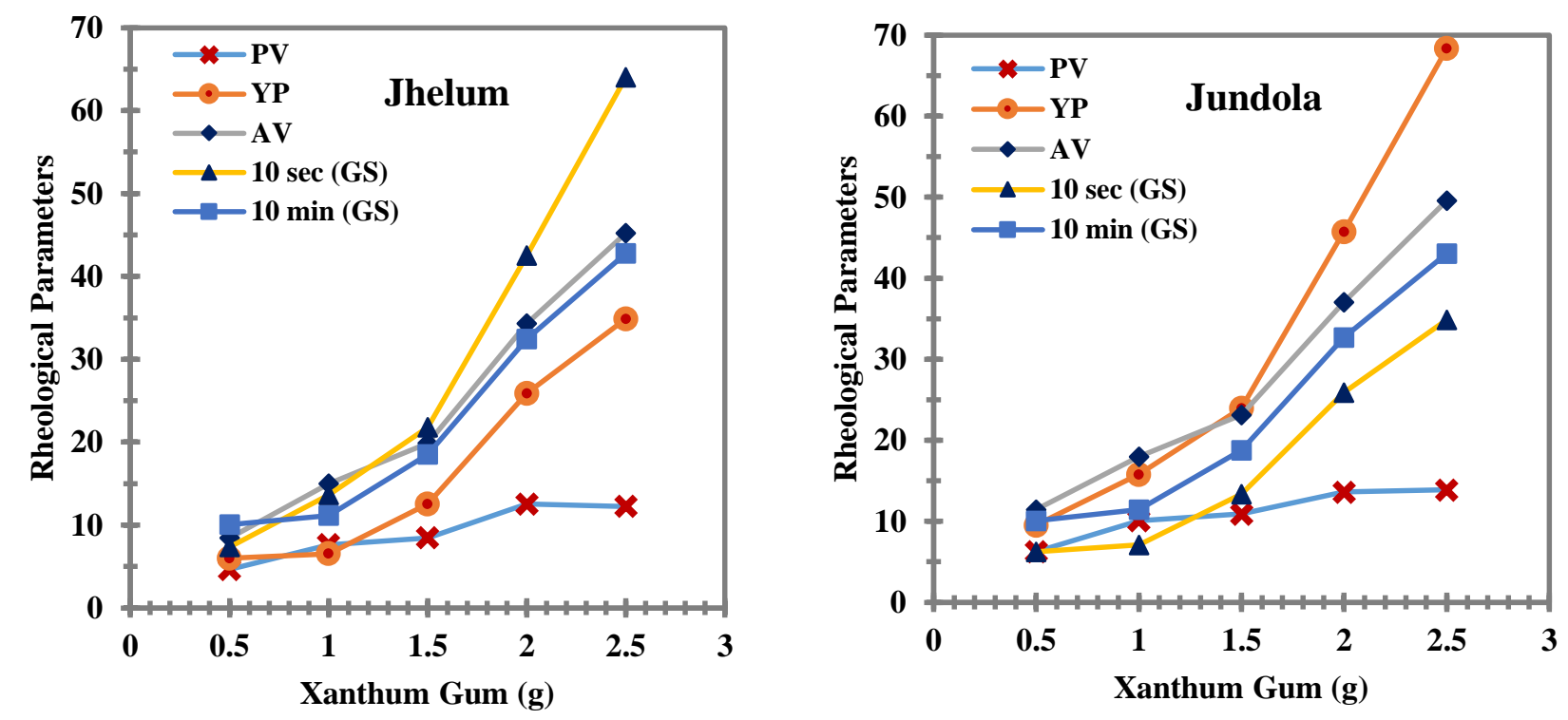

Fig. (8). Variation of rheological parameters with Xanthum Gumin 6\% (21g/350ml) by mass mud sample of Jhelum and Jundola.

When Jundola bentonite was also compared with the Jhelum bentonite, the former exhibited a great increase in the rheological parameters (plastic viscosity, apparent viscosity, yield point and gel strength) at the same concentrations of both bentonite clays $(21 \mathrm{~g} / 350 \mathrm{~mL})$ and additives. The combined effect of the constant amount of Xanthan gum (1g) and varied amount of carboxymethyl cellulose was observed. High viscosity (CMC HV) indicated an excellent result in controlling both the rheological and filtration properties as shown in Figs. $(\mathbf{9}, \mathbf{1 0})$. When 5\% Xanthan gum and 9.5\% CML HV were added to $21 \mathrm{~g} / 350 \mathrm{~mL}$ Jhelum mud, the dial reading at $600 \mathrm{rpm}$ greatly increased from 5 to 63 . It has given 11.5 folds increase in the dial readings and enhanced plastic viscosity and yield point to 8 and 31 times, respectively. This showed a rheological requirement for drilling purpose and met the API standards. The Jundola bentonite revealed better result in plastic viscosity, yield point and formation of gel strength than Jhelum bentonite.
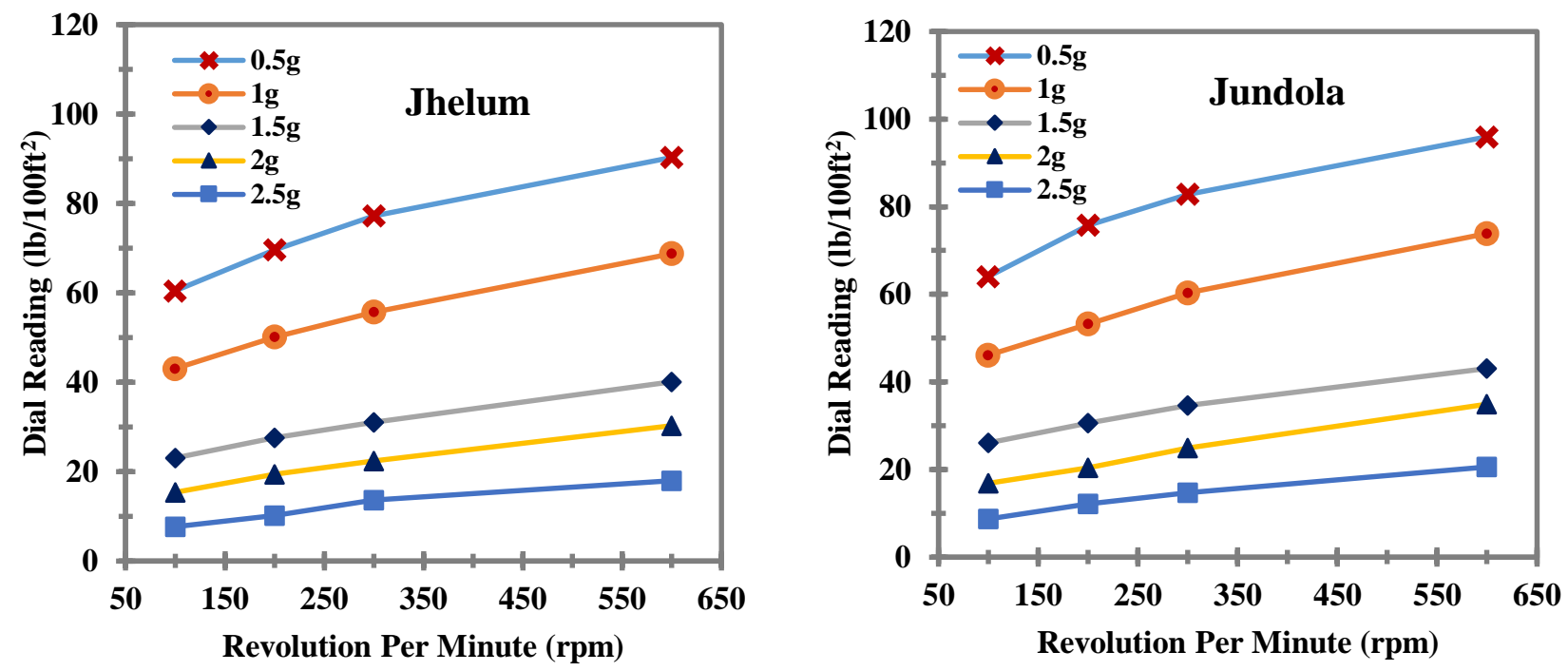

Fig. (9). Performance of (1g) Xanthan Gum and varying CMC HV with Jhelum \& Jundola clay mud samples in viscometer. 

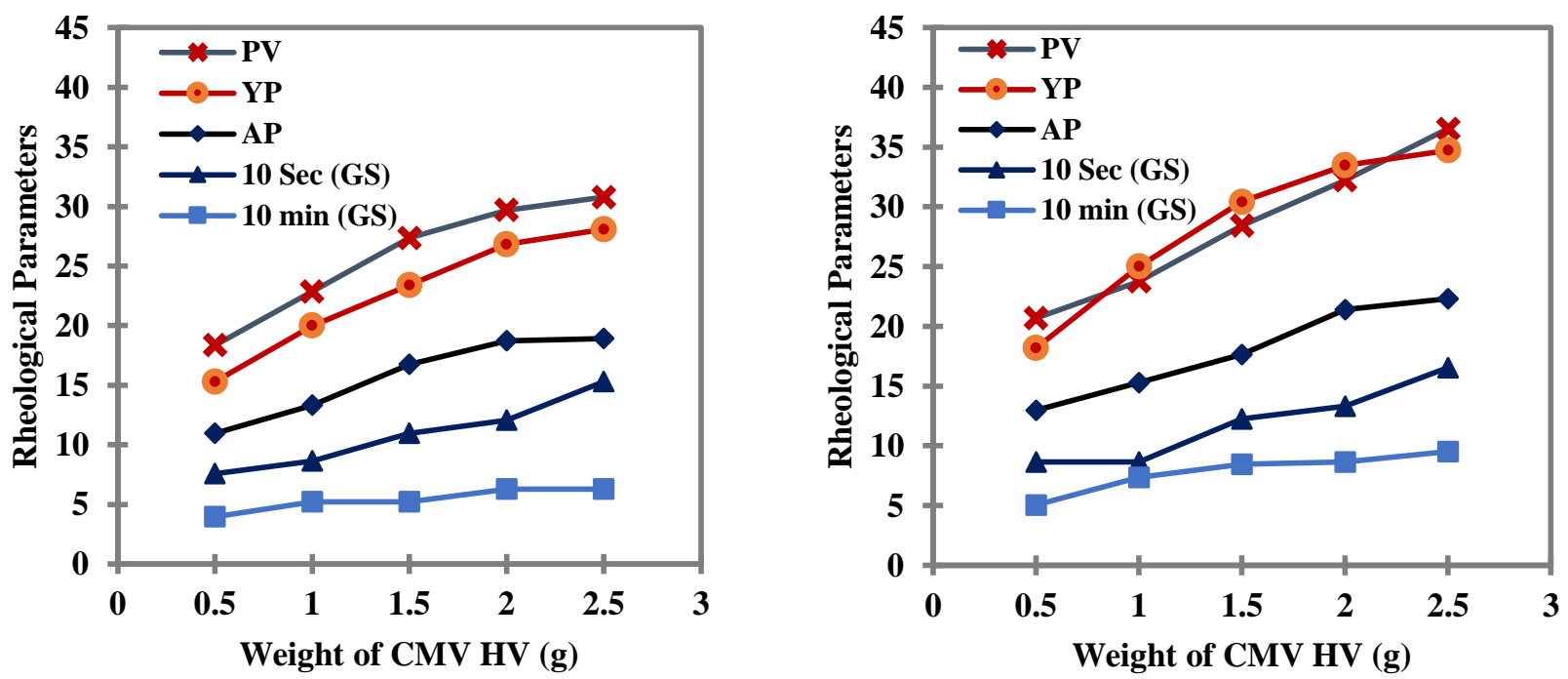

Fig. (10). Variation of rheological parameters with varying CMC HV and $1 \mathrm{~g}(\mathrm{XG})$ in $6 \%(21 \mathrm{~g} / 350 \mathrm{ml})$ by mass mud sample of Jhelum \& Jundola bentonite.

\subsubsection{Filtration Properties of Improved Jhelum and Jundola Bentonite:}

The filtration properties of Jhelum and Jundola muds under the combined effect of CMC HV + Xanthan gum at standard clay concentration $(21 \mathrm{~g} / 350 \mathrm{~mL})$ are presented in Fig. (11a). There was a drastic decrease in the filtrate loss as the amount of CMC HV in the mud was increased. When 7\% CMC (HV) and $1 \mathrm{~g}$ of Xanthan gum were added to the Jhelum bentonite mud samples, a reduced filtrate loss was noted i. e., 3.4 times to its original loss. This decrease in filtrate loss of the clay showed that the beneficiation improved the ability of the clay particles to remain in the suspension. As compared to Jhelum bentonite, the Jundola bentonite mud showed a better result in controlling the filtrate loss behavior of mud at the same concentration of additives.

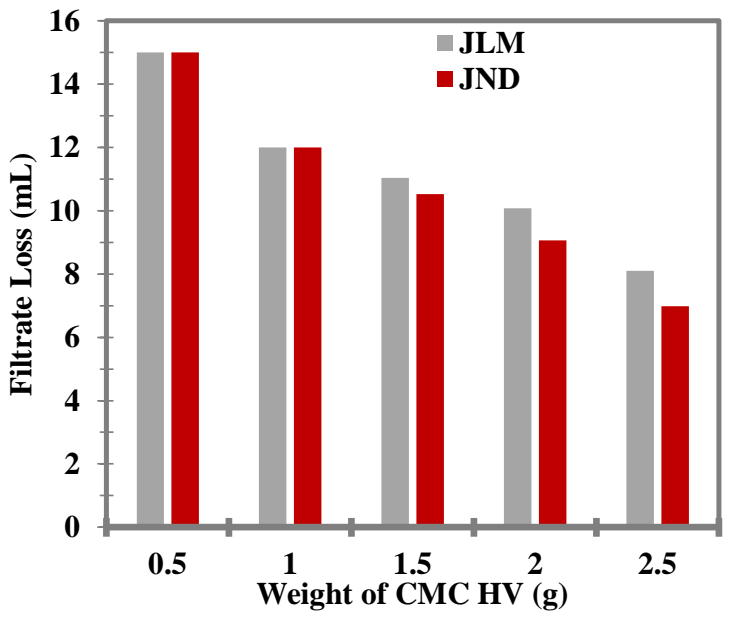

(a)

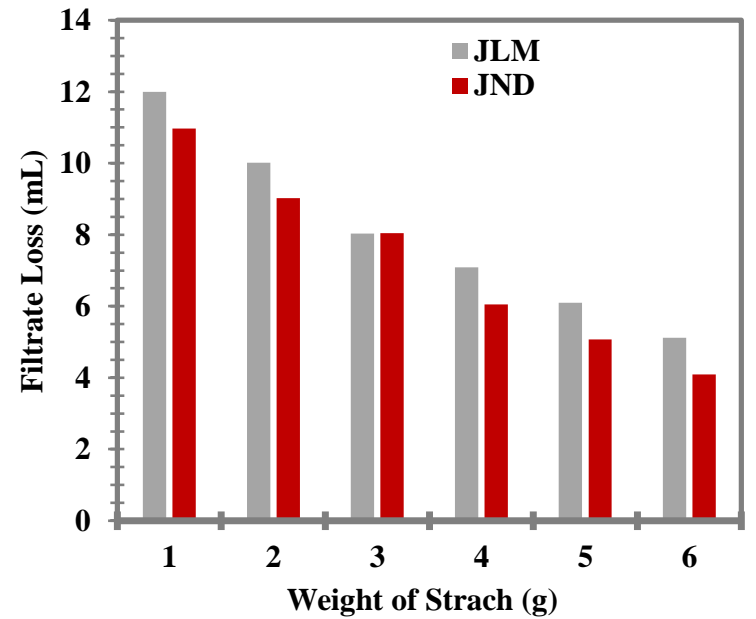

(b)

Fig. (11). (a) Filtration properties of the Jhelum (JLM) and Jundola (JND) improved with varying CMC HV and constant $1 \mathrm{~g}$ of Xanthan Gum; (b) Filtration properties of the starch and XG (1g) improved with Jhelum (JLM) \& Jundola (JND) clay mud.

The filtration properties for both bentonites were evaluated by adding Starch and Xanthan gum together at standard clay concentration $(21 \mathrm{~g} / 350 \mathrm{Ml})$. The starch beneficiated Jhelum samples gave an improvement in the filtration properties as shown in Fig. (11b). An addition of 12\% starch and Xanthan gum to beneficiate the Jhelum mud samples resulted in 3.7 folds reduction in the filtrate loss. This could be explained by the suspending and flocculating properties of starch. Similarly, there was a reduction of about $55 \%$ and $33 \%$ in the mud cake thickness as starch and CMC HV was 
used to support the local mud. The rate at which fluid was lost is a function of the thickness of filter cake. The decrease in the filtrate loss and mud cake thickness of the Jhelum and Jundola muds improved the overall ability of the mud to minimize the issue which normally occurs because of high filtrate.

\section{CONCLUSION}

Locally available raw bentonite from Jhelum and Jhandola areas were improved by adding additives such as Xanthum gum, CMC HV and starch to fulfill the API requirements. With the increase of clay concentration, both the filtration and rheological properties were improved and the optimum concentrations of $80 \mathrm{~g} / 350 \mathrm{~mL}$ for Jhelum and 60 $\mathrm{g} / 350 \mathrm{~mL}$ for Jundola bentonite were found. When beneficiated at $21 \mathrm{~g} / 350 \mathrm{~mL}$ with $9.5 \%$ Xanthan gum, clay exhibited 13 folds increase in the dial readings that gave an increase of 6.5 and 40 times in the plastic viscosity and yield point, respectively. The addition of $12 \%$ starch and $1 \mathrm{~g}$ Xanthan gum to upgrade the Jhelum mud samples resulted in 3.7 folds reduction in the filtrate loss and 55\% and 33\% in mud cake thickness, respectively. It is concluded that both Jhelum and Jundola bentonite has the potential to substitute the commercial bentonite and met the API standards when they were improved with Xanthum gum, CMC HV and starch. Further research is needed to evaluate the properties of the local mud by adding some locally available low-cost additives to enhance its rheological properties and filtration loss to fulfill the API standard for oil-well drilling.

\section{ETHICS APPROVAL AND CONSENT TO PARTICIPATE}

Not applicable.

\section{CONSENT FOR PUBLICATION}

Not applicable.

\section{CONFLICT OF INTEREST}

The authors declare no conflict of interest, financial or otherwise.

\section{ACKNOWLEDGEMENTS}

We want to thank MOL (Oil and Gas Co.) Pakistan and Baker Hughes (oil well drilling company) for allowing us to perform our testing in their state of the art labs.

\section{REFERENCES}

[1] S.J. leford, Ed., Industrial Minerals and Rocks, society of Mining Engineers of the American institute Mining Metallurgical and petroleum Engineers: New York, 1983.

[2] J. Elzea, and H.H. Murray, Bentonite; Industrial Minerals and Rocks., $6^{\text {th }}$ ed, Society for Mining, Metallurgy, and Exploration: Littleton, Colorado, 1994.

[3] D.D. Eisenhour, and R.K. Brown, "Bentonite and its impact on modern life", Elements, vol. 5, pp. 83-88, 2009.

[4] G. Christidis, and D.H. Huff, "Geologic aspects and genesis of bentonites", Elements, vol. 5, pp. 93-98, 2009. [http://dx.doi.org/10.2113/gselements.5.2.93]

[5] I.E. Odom, "Na-Ca montmorillonite: properties and uses", Transactions of metallurgical society of A.I.M.E, vol. 282, pp. 1893-1901, 1987.

[6] F.S. Antonio, and M. Madelyn, "Waste Management of Emergency Construction work. Case Study: 40 Dwellings in Seville (Spain)", Open Construction and Building Technology Journal, vol. 11, pp. 110-123, 2017. [http://dx.doi.org/10.2174/1874836801711010110]

[7] N.G. Maldonado, P.E. Martin, and I.A. Maldonado, "Seismic mitigation of a historic masonry building", Open Construction and Building Technology Journal, vol. 5, pp. 61-70, 2011. [http://dx.doi.org/10.2174/1874836801105010061]

[8] P.W. Harben, The Industrial Minerals Handybook., $2^{\text {nd }}$ ed, Industrial Minerals Information Ltd.: London, 1995.

[9] G.J. Churchman, M. Askary, P. Peter, M. Wright, M.D. Raven, and G.S. Peter, "Geotechnical properties indicating environmental uses for an unusual Australian bentonite", Applied Clay Science, vol. 20, pp. 199-209, 2002. [http://dx.doi.org/10.1016/S0169-1317(01)00078-3]

[10] W.A. Allo, and H.H. Murray, "Mineralogy, chemistry and potential applications of a white bentonite in San Juan province, Argentina", Applied Clay Science, vol. 25, pp. 237-243, 2004. [http://dx.doi.org/10.1016/j.clay.2003.10.003]

[11] F. Bergaya, and G. Lagaly, "Handbook in Clay Science", Developments in Clay Science, vol. 5, pp. 1-813, 2013. 
[12] H.H. Murray, "Applied clay mineralogy: Occurrences, processing and application of kaolins, bentonites, palygorskite-sepiolite, and common clays", Developments in Clay Science, vol. 2, pp. 1-80, 2006. [http://dx.doi.org/10.1016/S1572-4352(06)02001-0]

[13] N. Güven, "Bentonites-clays for molecular engineering", Elements, vol. 5, pp. 89-92, 2009. [http://dx.doi.org/10.2113/gselements.5.2.89]

[14] I.E. Odom, "Smectite clay minerals", Phylosiphical Transactions of Royal Society of London A: Mathematical, Physical and Engineering Science, vol. 311, pp. 391-409, 1984. [http://dx.doi.org/10.1098/rsta.1984.0036]

[15] G. Christidis, and P.W. Scott, "Laboratory evaluation of bentonites", Industrial Minerals, vol. 311, pp. 51-57, 1993.

[16] S.T. Ali, and I. Shah, "The bentonite resources of Pakistan", CENTO Symposium on Industrial Rocks and Minerals, pp. $153-160,1963$.

[17] M. Alauddin, M.A. Qaiser, S.M. Akhtar, and A.H. Khan, "Mineralogy and chemistry of Dheri-Kot clays, Campbellpur (Attock) district, Rawalpindi Division", Pakistan Journal of Scientific and Industrial Research, vol. 8, pp. 343-346, 1965.

[18] M. Safdar, A. Hamid, and M.A. Naz, "A study of a high alumina clay from Musakhel", Pakistan Journal of Scientific and Industrial Research, vol. 9, pp. 224-229, 1966

[19] M. Ashraf, M. Ahmad, and F.A. Faruqi, "Jurassic bauxite and kaolinite deposits of Chhoi area, Kala Chitta Range, Punjab", Geological Bulletin Punjab University, vol. 12, pp. 41-54, 1976.

[20] T. Hussain, and A.A. Naqvi, "High alumina clay deposits of the Punjab Province, Pakistan", Geological Survey of Pakistan, Information Release No. 59, 1972.

[21] S.N. Khan, and A. Hussain, "Mineralogy and physical properties of bauxite - high alumina clay deposits of Katha-Pail area, Tehsil Khushab District, Sargodha, Punjab", Geological Survey of Pakistan, Information Release No. 37, 1970.

[22] Z. Ahmad, and R.A. Siddiqi, Minerals and Rocks for Industry., Geological Survey of Pakistan, 1992.

[23] G. Whitney, S.Q. Abbas, and K. Esposito, "Mineralogy and thermal properties of clay deposits in the salt range and kala chitta range, Punjab province, Pakistan", US. Geological survey, Open-File Report 90-657, 1990.

[24] L.A. Shah, N.S. Khattak, M.G. Valenzuela, A. Manan, and F.R. Valenzuela Diaz, "Preparation and characterization of purified Na-activated bentonite from Karak (Pakistan) for pharmaceutical use", Clay Minerals, vol. 48, pp. 595-603, 2013. [http://dx.doi.org/10.1180/claymin.2013.048.4.03]

[25] "Bringing Mining In Pakistan Up To International Standards. Appendix 3 - Provincial mining industry in Pakistan", Canada-Pakistan Chamber of Commerce, 2013. Available at: www.cpcoc.org

[26] S. Nasreen, A. Ghani, and S. Noor, "Evaluation and Activation of Cambalpur Bentonite for Industrial Utilization", Pakistan Journal Science Industrial Research, vol. 53, pp. 123-126, 2010.

[27] R. Bibi, W.A. Shah, and M.I. Chaudry, "Effect of pH and concentration on the removal of magnesium from magnesium chloride solution by bentonite", Pakistan Journal Science Industrial Research, vol. 47, pp. 336-339, 2004.

[28] S. Nasreen, and M. Zubair, "F.A. Siddiqi M.A. Qaiser, A.H. Khan, "Studies on some indigenous materials for their puzzolanic properties", Journal of Islamic Academy of Sciences, vol. 2, pp. 172-176, 1989.

[29] J. Mirza, M. Riaz, A. Naseer, F. Rehman, A.N. Khan, and Q. Ali, "Pakistani bentonite in mortar and concrete as low-cost construction material", Applied Clay Science, vol. 45, pp. 220-226, 2009. [http://dx.doi.org/10.1016/j.clay.2009.06.011]

[30] S.S. Ahmad, A. Barbhuiya, A. Elahi, and J. Iqbal, "Effect of Pakistani bentonite on properties of mortar and concrete", Clay Minerals, vol. 46, pp. $85-92,2011$. [http://dx.doi.org/10.1180/claymin.2011.046.1.85]

[31] S.A. Memon, R. Arsalan, S. Khan, and T.Y. Lo, "Utilization of Pakistani bentonite as partial replacement of cement in concrete", Construction and Building Materials, vol. 30, pp. 237-242, 2012.

[http://dx.doi.org/10.1016/j.conbuildmat.2011.11.021]

[32] C. Karagüzel, T. Çetinel, F. Boylu, K. Çinku, and M.S. Çelik, "Activation of (Na, Ca)-bentonites with soda and MgO and their utilization as drilling mud", Applied Clay Science, vol. 48, pp. 398-404, 2010. [http://dx.doi.org/10.1016/j.clay.2010.01.013]

[33] "American Petroleum Institute. Specification for drilling-fluid materials includes errata", American Petroleum Institute, Seventeenth Edition, API 13A, 2006.

[34] J.L. Lumus, and T. Okla, "Method of drilling with polymer-treated drilling fluid", US Patent, US3472325, 1969.

[35] J.E. Glass-Jr, "Hec-bentonite compatible blends", US-Patent 4561985, 31, 1985.

[36] C.L. Burdick, "Aqueous systems comprising an ionic polymer and a viscosity promoter, processes for their preparation, and uses thereof", US-Patent 4561985, 2002.

[37] M.S. Hassan, and N.A. Abdel-Khalek, "Beneficiation and applications of an Egyptian Bentonite", Applied Clay Science, vol. 13, pp. 99-115, 1998. 
[http://dx.doi.org/10.1016/S0169-1317(98)00021-0]

[38] "A. O. Olatunde1, M. A. Usman1, O. A. Olafadehan1, T. A. Adeosun, O.E. Ufot, Improvement of rheological properties of drilling fluid using locally based materials", Petroleum and Coal, vol. 54, pp. 65-75, 2012.

[39] M.I. Abdou, and H. Abuseda, "Improving the performance of clay from Gabal Um Qumar as drilling mud", Egyptian Journal of Petroleum, vol. 23, pp. 213-220, 2014.

[40] "M.1. Omotioma, P.C.N. Ejikeme, J.I. Ume, "Improving the rheological properties of water based mud with the addition of cassava starch", I.O.S.R.-", Journal of Applied Chemistry, vol. 8, pp. 70-73, 2015.

[41] O.C. Wilfred, and A.E. Akinade, "Comparative study of basic properties of mud prepared with nigerian local clay and mud prepared with foreign clay: A case study of abbi clay deposit", International Journal of Engineering and Technologies, vol. 8, pp. 61-71, 2016. [http://dx.doi.org/10.18052/www.scipress.com/IJET.8.61]

[42] J.A. Nattier, and T.G. Shumate, "Weight material for drilling friends and method of creating and maintaning the disvied weight", US-Patent $6180573,30,2010$.

[43] O.A. Falode, O.A. Ehinola, and P.C. Nebeife, "Evaluation of local bentonitic clay as oil well drilling fluids in Nigeria", Applied Clay Science, vol. 39, pp. 19-27, 2008. [http://dx.doi.org/10.1016/j.clay.2007.04.011]

\section{(C) 2017 Khan et al.}

This is an open access article distributed under the terms of the Creative Commons Attribution 4.0 International Public License (CC-BY 4.0), a copy of which is available at: https://creativecommons.org/licenses/by/4.0/legalcode. This license permits unrestricted use, distribution, and reproduction in any medium, provided the original author and source are credited. 